\title{
A dramatização no contexto da história da enfermagem: um relato de experiência
}

The dramatization in the context of nursing history: an experience report

La dramatización en el contexto de la historia de la enfermería: relato de experiencia

\author{
Bárbara Misslane da Cruz Castro ${ }^{1 *}$, lago Orleans Pinheiro Monteiro².
}

\begin{abstract}
RESUMO
Objetivo: Relatar a experiência vivenciada através da dramatização no desenvolvimento da disciplina de "Contexto Histórico Social da Enfermagem". Métodos: O presente estudo trata-se de um relato de experiência sobre a dramatização do contexto histórico da Enfermagem apresentada na $2^{\circ}$ Semana de Enfermagem da Universidade Federal do Amazonas, realizada no período de maio de 2015. Resultados: A dramatização é considerada uma metodologia ativa complexa de ser trabalhada, tendo em vista exigir um processo de preparo que direcione a efetividade da ação. Nesse contexto, este método de ensino vem ganhando espaço nas instituições e sendo incorporado na formação dos enfermeiros. Na experiência vivenciada, os acadêmicos foram oportunizados ao trabalho em equipe e se apropriaram dos conhecimentos inerentes à história da profissão. Conclusão: $O$ desenvolvimento da peça teatral demonstrou ser de grande valia, uma vez que este método permitiu aos discentes aprofundar seus conhecimentos em relação ao contexto histórico da enfermagem.
\end{abstract}

Palavras-chave: Educação em Saúde, Educação em Enfermagem, História da Enfermagem.

\begin{abstract}
Objective: To report the lived experience through the dramatization in the development of the discipline of "Historical Social Context of Nursing". Methods: The present study is an experience report about the role of the historical context of Nursing presented at the 2nd Nursing Week of the Federal University of Amazonas, held in May 2015. Results: The role play is considered a methodology active process of being worked, in order to demand a process of preparation that directs the effectiveness of the action. In this context, this method of teaching has been gaining ground in institutions and being incorporated into the training of nurses. In the lived experience, the academics were given the opportunity to work as a team and appropriated the knowledge inherent in the history of the profession. Conclusion: The development of the play proved to be of great value, since this method allowed the students to deepen their knowledge regarding the historical context of nursing.
\end{abstract}

Keywords: Health education, Nursing Education, History of Nursing.

\section{RESUMEN}

Objetivo: Informar la experiencia vivenciada a través de la dramatización en el desarrollo de la disciplina de "Contexto Histórico Social de la Enfermería". Métodos: El presente estudio se trata de un relato de experiencia sobre la dramatización del contexto histórico de la Enfermería presentada en la $2^{\text {a }}$ Semana de Enfermería de la Universidad Federal del Amazonas, realizada en el período de mayo de 2015. Resultados: La dramatización es considerada una metodología que es compleja de ser trabajada, con el fin de exigir un proceso de preparación que dirija la efectividad de la acción. En este contexto, este método de enseñanza

\footnotetext{
${ }^{1}$ Enfermeira Mestre em Saúde Pública Instituto Leônidas e Maria Deane/ Fiocruz Amazônia. Manaus-AM.

${ }^{2}$ Acadêmico de Enfermagem. Universidade Federal do Amazonas-UFAM. Manaus-AM.

*E-mail: barbaramisslane@hotmail.com
}

SUBMETIDO EM: 10/2018

ACEITO EM: 11/2018

PUBLICADO EM: 01/2019

REAS/EJCH | Vol. 11 (2) | e256 | DOI: https://doi.org/10.25248/reas.e256.2019 Página 1 de 6 
viene ganando espacio en las instituciones y siendo incorporado en la formación de los enfermeros. En la experiencia vivenciada, los académicos fueron oportunizados al trabajo en equipo y se apropiaron de los conocimientos inherentes a la historia de la profesión. Conclusión: El desarrollo de la pieza teatral demostró ser de gran valor, ya que este método permitió a los alumnos profundizar sus conocimientos en relación al contexto histórico de la enfermería.

Palavras-clave: Educación en Salud, Educación en Enfermería, Historia de la Enfermería.

\section{INTRODUÇÃO}

A prática didática ao longo dos anos vem exigindo a incorporação de elementos pedagógicos que possibilitem ao aluno o exercício pleno do pensamento crítico, superando o modelo de ensino centrado na transmissão de conhecimentos por parte do educador e o recebimento passivo e incontestado dos mesmos pelo educando (PEREIRA, 2003).

Nesse sentido, no campo da educação, vê-se a necessidade de preparar indivíduos mais autônomos favorecendo a formação de profissionais críticos, reflexivos e com maior facilidade para tomada de decisões (FREIRE, 2005).

As metodologias de ensino que procuram desenvolver a autonomia do educando assim como o autogerenciamento e corresponsabilidade pelo seu próprio processo de formação são denominadas de metodologias ativas de aprendizagem (MITRE, 2008). Alguns exemplos dessas metodologias são: estudo de caso, processo do incidente, método de projetos, pesquisa científica, aprendizagem baseada em evidências, tempestade cerebral, mapa conceitual, oficina, júri simulado, portfólio, seminário, oficina, dramatização (BERBEL, 2011; BORDENAVE e PEREIRA, 1982).

Estudos como o de Tobase et al. (2007), Rampaso et al. (2011), Boctor (2013) e Christofoletti et al. (2014) apontam que as metodologias ativas utilizadas no processo de ensino-aprendizagem são capazes de produzir grandes resultados, como maior satisfação dos alunos com o ensino e melhores níveis de aprendizado.

Corroborando com os resultados positivos de que o ensino baseado na "problematização" e na construção educacional colaborativa que colocam o aluno e o educador no mesmo nível de importância, o estudo de Reeve (2009) elencou as principais mudanças de comportamento dos alunos em práticas didáticas ativas, como: percepção de competência, pertencimento, curiosidade, internalização de valores, maior presença nas aulas, baixa reprovação, baixa evasão escolar, preferência por desafios ótimos, criatividade, melhor entendimento conceitual, processamento profundo de informações, uso de estratégias autorreguladas, melhoria do desempenho em notas, sensação de bem-estar e satisfação com a vida.

Considerando a importância de inserir as metodologias ativas nos processos pedagógicos, os cursos de graduação da área da saúde têm sido cada vez mais estimulados a incluírem no processo de ensinarem elementos que ampliem o desenvolvimento assíduo de profissionais mais humanísticos e reflexivos.

São notórias no documento das Diretrizes Curriculares Nacionais do Curso de Graduação em Enfermagem, as características que norteiam a formação de profissionais para o exercício da profissão com base no rigor científico e intelectual e pautado em princípios éticos, capazes de atuar no mundo de maneira contextualizada com base na cidadania, criticidade e criatividade (BRASIL, 2001).

Compreendendo a importância do uso de metodologias ativas na formação profissional buscou-se através de uma experiência com uso da Dramatização possibilitar aos alunos a aproximação com a realidade concreta e a oportunidade de refletirem sobre o contexto social e cultural da situação vivenciada, de modo que favoreça o enfrentamento e a resolução de conflitos.

Deste modo, este estudo busca relatar a experiência vivenciada através da dramatização no contexto da disciplina de "Contexto Histórico Social da Enfermagem" desenvolvida na $2^{2}$ Semana de Enfermagem da Universidade Federal do Amazonas, em maio de 2015. 


\section{MÉTODOS}

Trata-se de um relato de experiência vivenciado a partir da construção de uma peça teatral na disciplina de Contexto Histórico Social da Enfermagem apresentada durante a $2^{\text {a }}$ Semana de Enfermagem da Universidade Federal do Amazonas realizada no período de 12 a 20 de maio de 2015.

A experiência deu-se durante o desenvolvimento da disciplina "Contexto Histórico Social da Enfermagem", a qual é oferecida no primeiro semestre do ano letivo, com carga horária total de 30 horas, propiciando ao estudante a oportunidade de conhecer de modo sistemático e sequencial os períodos da história da enfermagem.

O planejamento para a atividade teatral deu-se previamente em conformidade ao plano da disciplina estabelecido pela professora titular que definiu como critério avaliativo final a realização de uma peça teatral que narrasse e demonstrasse os períodos de desenvolvimento da enfermagem até de fato ser reconhecida como ciência.

Os alunos ficaram encarregados de organizar e estruturar toda a dramatização: peça, cenário, roteiro, ensaio, passagem de som, figurino, bem como de realizar um levantamento bibliográfico de todo 0 conhecimento produzido e adquirido nas aulas teóricas sobre a história da enfermagem e nas bases dados da saúde.

A peça teatral intitulou-se de "Enfermagem na História da Humanidade". Contou com a participação de 40 discentes responsáveis pela organização, ornamentação, e caracterização dos personagens e 123 convidados, entre membros do corpo docente, alunos de outras turmas e familiares dos discentes envolvidos na construção da peça teatral.

\section{RESULTADOS E DISCUSSÃO}

A dramatização está sendo cada vez mais incorporada por educadores da área da saúde, e, sobretudo, incorporada a formação do enfermeiro. Uma revisão integrativa identificou que a dramatização no ensino da enfermagem é de amplitude internacional, com predominância de pesquisas de origem americana e inglesa, e alguns estudos de origem espanhola e brasileira, centradas principalmente na preocupação de formadores com a quebra do paradigma do ensino baseado na pedagogia tradicional (TOBASE; GESTEIRA e TAKAHASHI, 2007).

Tobase, Gesteira e Takahashi (2007) definem três modalidades de estratégia de dramatização mais utilizadas no processo de ensino-aprendizagem: o sociodrama/psicodrama, que prioriza e permite avaliar a interação e as relações no grupo; o role playing, ou jogo de papéis, que possibilita, aos envolvidos no processo de ensino, assumirem um papel social que não é o seu; e a oficina de educação em saúde, metodologia voltada para ações de educação em saúde articulada com a cultura da comunidade.

A peça teatral "Enfermagem na História da Humanidade" realizada na $2^{a}$ Semana de Enfermagem da Escola de Enfermagem de Manaus trouxe grandes proporções de conhecimento histórico, tanto para os alunos/atores, quanto para os convidados que prestigiaram o evento.

A realização da atividade exigiu uma preparação que compreendeu desde a elaboração do texto até a montagem do cenário e apresentação, foi relevante a contribuição dos alunos, e todo esse processo impulsionou o aprofundamento na história da enfermagem, pois todas as etapas de construção da apresentação tinham o dever de deixar o enredo histórico da profissão explicito a todo público.

A dramatização pode ser considerada um dos métodos mais complexos das metodologias ativas, pois exige uma preparação mais rigorosa do que a própria aula expositiva. É importante que ao definir a dramatização como método de ensinagem, os atores envolvidos nesse processo percorram etapas importantes, como: tomar conhecimento dos objetivos e finalidade do estudo, compreender aplicabilidade do conteúdo em sua vida profissional e a buscar informações necessárias para a elaboração da dramatização (BARROS e CYRILLO, 2006). 
Tendo em vista o reconhecimento da importância do profissional de enfermagem dominar a história da profissão, todos os anos a professora que ministra a disciplina "Contexto Histórico da Enfermagem" no primeiro período do curso avalia os graduandos através de peças teatrais que são divididas em épocas e civilizações, por meio dessa metodologia inovadora é possível à fixação dos conteúdos e a valorização do aprendizado.

Segundo Tobase, Gesteira e Takahashi (2007) este método de ensino-aprendizagem é capaz de proporcionar aos alunos aperfeiçoamento individual e coletivo, pois a atividade interativa desenvolve o trabalho participativo, desperta ao sujeito a consciência da importância de um trabalho em grupo, além de vincular a teoria como elemento para análise, reflexão, raciocínio e tomada de decisão.

Sousa (2010) elucida que na dramatização os alunos são os atores principais do processo didático, formulam suas próprias frases, determinam a direção da cena e o professor se faz presente para transformar o acontecimento em uma experiência e aprendizado significativo.

De acordo com Sousa (2010), através da dramatização, o aluno tem a possibilidade de transformar a realidade em que se encontra, representando por vezes o que de fato gostaria que tivesse acontecido e de forma inconsciente expressa o que mais Ihe afeta assim como aquilo que the faz sofrer.

O aprofundamento na história da profissão levou os alunos a compreenderem o valor que deve ser dado aos ideais e obstáculos vencidos pelas enfermeiras nos tempos antigos, além de capacitá-los para a resolução de problemas referentes à profissão nos tempos atuais, buscando na história respostas para situações presentes.

Oguisso (2007) afirma que é importante que o acadêmico possua atitude de um historiador. Recorrer ao passado se faz necessário, já que o conhecimento histórico é construído com o mergulho no tempo, nesse sentido a atividade realizada facilitou esse processo, pois o princípio o olhar do historiador ou daquele que lida com fatos históricos deve, necessariamente, ser remetido para o passado, mesmo que recente, pois a história não trabalha com previsões futuras, mas com acontecimentos do passado, mesmo enquanto projetos.

Vivenciar essa atividade dinamizou a continuidade do curso, estreitando os relacionamentos e o contato grupal, além de ter aprimorado a carga de conhecimento dos graduandos, ratificando o cuidar como objeto principal do trabalho como enfermeiro (a), já que o enredo histórico expõe esse fator como um dos principais para o engrandecimento da profissão. Por fim, os vivenciados dessa experiência ampliaram sua visão ética e profissional devido aos fatores históricos que tornaram a Enfermagem o que é hoje.

Um relato de experiência desenvolvido por docentes de graduação em enfermagem no contexto da disciplina de Planejamento e Administração em Enfermagem no processo de avaliação do desenvolvimento de uma dramatização refuta que, a atividade permitiu aos discentes vivenciarem situações reais, concretas e de real significância para o aprendizado. A presença do público demonstrou-se positiva tendo em vista que os discentes/atores se preocuparam em representar com exatidão e clareza sobre as práticas gerenciais do enfermeiro (KALINOWSKI et al., 2013).

Um estudo descritivo de natureza qualitativa, realizado com 199 alunos do primeiro ano do curso de enfermagem que participaram de uma dramatização realizada na disciplina de História da Enfermagem em um centro universitário de São Paulo, evidenciou que a maioria dos alunos respondeu que a atividade contribuiu de forma significativa para a formação do conhecimento em história da enfermagem e consideram importante a utilização da metodologia da dramatização no processo de ensino-aprendizagem (BARROS e CYRILLO, 2006).

O role play ou troca de papéis tem sido cada vez mais reconhecido como elemento importante no processo de aprendizagem e comunicação. Considerando que a encenação de papeis coloca o aluno na condição de paciente, e como estratégia de dramatização o role play sem sombra de dúvidas é capaz de humanizar e dinamizar o ensino no contexto da saúde (RABELO e GARCIA, 2015). 
O jogo de papéis, que a dramatização possibilita, pressupõe ao discente que assuma uma função social que não é a sua, além de facilitar a compreensão das atitudes e decisões do outro, e treina habilidades necessárias e requeridas para, no presente caso, o trabalho em saúde; permite também que o próprio grupo elabore gradualmente uma história para que papéis ou personagens sejam incorporados.

O estudo de Negri et al. (2017) identificou através de uma revisão bibliográfica que dentre as estratégias de dramatização empregadas destacaram-se o uso do paciente simulado (ator treinado) e do role play (encenação de papéis). E os ganhos percebidos pelos discentes a partir das encenações foram de aprimoramento de conhecimento, desenvolvimento de habilidades, diminuição de ansiedade, satisfação com o processo de ensino-apredizagem, autoconfiança, motivação em aprender, capacidade de reflexão e pensamento crítico e fortalecimento do trabalho em equipe.

Observa-se no estudo de Aragão et al., (2009) que a técnica de role-playing como método de sensibilização dos alunos de Medicina para o exame ginecológico é capaz de despertar nos mesmos quando adotam a condição de paciente sobre o melhor preparo para a vida profissional, empatia e sobretudo reflexões importantes de humanização no cuidado ao paciente e fortalecimento das relações interpessoais.

Frente ao exposto neste estudo, compreende-se que a dramatização é um método que deve ser amplamente explorado, tendo em vista que repercute de forma positiva e significativa para o aprendizado além de contribuir com a formação de profissionais mais humanísticos e formadores de opinião.

\section{CONCLUSÃO}

Para a formação de profissionais cientes de suas atribuições e da relevância do seu papel social, as instituições de ensino devem promover além do conhecimento técnico, a inserção dos estudantes em seu contexto de vivência e, para que isso seja realizado de forma completa considera-se importante transmitir toda a história da enfermagem. Dessa forma, os estudantes passam a entender os motivos pelos quais a enfermagem originou-se e agregado a isso, aprendem a valorizar e reconhecer quem exerceu e desenvolveu está profissão. Para abordagem deste conteúdo durante a graduação, a docente da Escola de Enfermagem de Manaus decidiu por utilizar como método a dramatização. Esta metodologia demonstrou ser de grande valia, pois, oportunizou aos alunos aprofundarem seus conhecimentos na história da enfermagem e permitiu que os convidados ao assistir à peça realizada na $2^{\circ}$ Semana de Enfermagem da Escola de Enfermagem de Manaus absorvessem a história, já que, este método facilita a compreensão do assunto abordado. Portanto, a experiencia reafirmou a dramatização como ferramenta pedagógica eficaz para o ensino da história da enfermagem. A partir disto, sugere-se a replicação em outros contextos, com vista, à formação de profissionais de enfermagem cientes do seu papel e da importância que a profissão tem para o meio onde atuam.

\section{REFERÊNCIAS}

1. ARAGÃO JCS et al. O uso da técnica de role-playing como sensibilização dos alunos de Medicina para o exame ginecológico. Rev Bras Educ Med, 2009; 33(1): p. 80-3.

2. BARROS MA, CIRYLLO CCP. A dramatização como recurso no processo ensino-aprendizagem na disciplina de história da enfermagem. Cogitare enfermagem, 2006; 11(1): p. 44-49.

3. BERBEL NAN. As metodologias ativas e a promoção da autonomia de estudantes. Semina: Ciências Sociais e Humanas, 2001; 32(1): p. 25-40.

4. BOCTOR L. Active-learning strategies: The use of a game to reinforce learning in nursing education. A case studies. Nurse Education in Practice, 2013; 13(2): p. 96 - 100.

5. BORDENAVE JD, PEREIRA AM. Estratégias de ensino-aprendizagem. 4 td ed. Petrópolis: Vozes, 1982.

6. BRASIL. MINISTÉRIO DA EDUCAÇÃO. Resolução CNE/CES N 3, de 7/11/2001. Institui Diretrizes curriculares nacionais do curso de graduação em enfermagem. Diário Oficial da União, 2001; Seção 1. 
7. CHRISTOFOLETTI G, FERNANDES JM, MARTINS AS et al. Grau de satisfação discente frente à utilização de métodos ativos de aprendizagem em uma disciplina de Ética em saúde. Revista Eletrônica de Educação, 2014; 8(2): p. 188-197.

8. FREIRE P. Pedagogia do oprimido. 41 ed. Rio de Janeiro: Paz e Terra, 2005. 213p.

9. KALINOWSKI CE et al. Metodologias participativas no ensino da administração em Enfermagem. InterfaceComunicação, Saúde, Educação,2013; 17: p. 959-967.

10. MITRE SM, BATISTA RS, MEDONÇA JRG et al. Metodologias ativas de ensino-aprendizagem na formação profissional em saúde: debates atuais. Ciência \& Saúde Coletiva, 2008; 13 (Sup 2): p. 2133-2144.

11. NEGRI EC et al. Simulação clínica com dramatização: ganhos percebidos por estudantes e profissionais de saúde. Revista Latino-Americana de Enfermagem, 2017; 25: p. 2916.

12. OGUISSO, T (org.). Trajetória histórica e legal da enfermagem, 2nd ed. São Paulo: Manole, 2007.

13. PEREIRA, ALF. As tendências pedagógicas e a prática educativa nas ciências da saúde. Cadernos de Saúde Pública, 2003; 19(1): p. 1527-1534.

14. RABELO L, GARCIA VL. Role-Play para o Desenvolvimento de Habilidades de Comunicação e Relacionais. Rev. bras. educ. méd, 2015; 39 (4): p. 586-596. RAMPASO DAL, DORIA MAG, OLIVEIRA MCM et al. Teatro de fantoche como estratégia de ensino: relato da vivência. Revista Brasileira de Enfermagem, 2011; 64(4): p. 783-785.

15. REEVE J. Why teachers adopt a controlling motivating style toward students and how they can become more autonomy supportive. Educational Psychologist, Hillsdale, 2009; 44(3): p. 159-175.

16. SOUSA MMT. A Dramatização como Recurso Pedagógico em Enfermagem. Revista Pró-UniverSUS, 2010; 1(1): p. 01

17. TOBASE L; GESTEIRA ECG; TAKAHASHI RT. Revisão de literatura: a utilização da dramatização no ensino de enfermagem. Revista Eletrônica de Enfermagem, 2007; 9(1): p. 214-228. 